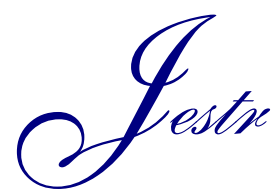

Research Article

www.jestr.org

\title{
Particle Swarm Optimization Backstepping Controller for a Grid-Connected PV/Wind Hybrid System
}

\author{
Mohcene Bechouat $^{1 *}$, Moussa Sedraoui ${ }^{1}$, Youcef Soufi $^{2}$, Laatra Yousfi $^{3}$, Abdelhalim Borni $^{4}$, Sami Kahla $^{1}$ \\ ${ }^{1}$ Laboratoire des télécommunications, Université 8 Mai 1945 Guelma, Alegria \\ ${ }^{2}$ Labget laboratory, Department of Electrical Engineering, University of Tebessa, Algeria \\ ${ }^{3}$ University of Tebessa, Algeria Laboratory Inverses Problems: Modeling, Information and Systems (PI:MIS) \\ ${ }^{4}$ Unité de Recherche Appliquée en Energies Renouvelables, URAER, Centre de Développement Des Energies Renouvelables, CDER, 47133 \\ Ghardaïa, Alegria
}

Received 13 July 2016; Accepted 11 February 2017

\begin{abstract}
The current paper investigates Backstepping controller using Particle Swarm Optimization for Photovoltaic "PV"/Wind hybrid system. The tested system was connected to the grid by three-phase inverter commissioned to address current depending on the grid parameters and still deliver its reactive power to zero. Backstepping control is a recursive methodology that uses Lyapunov function which can ensure the system stability. The best selection of Lyapunov function gains values should give a good result. In most of the literatures, the choice was based on the expertise of the studied system using hurwitzienne method considered as heuristic choice. The aim of this work is to propose an optimization using a powerful method commonly called Particle Swarm Optimization "PSO" able to calculate the gains values depending on the grid parameters by minimizing a selected criterion. The simulation results show that the PSO Backstepping controller gives good results shown in the current injected to grid with a small harmonic distortion despite climate change in the wind speed and the irradiation, which also shows the robustness of the applied control.
\end{abstract}

Keywords: PV/Wind Grid-Connected, MPPT, Backstepping Controller, PSO, Matlab/Simulink.

\section{Introduction}

World energy consumption is growing, posing critical questions about the global warming problem caused by gas emissions on the one hand and on the depletion of fossil resources on the other hand. Following this realization, the development of the economic and sustainable environment is absolutely necessary. In order to make the supply of more environmentally friendly electricity, new energy sources called "Renewable Energy" have been emerged [1]. Renewable Energy have the potential to generate electricity cleanly and especially in less dependence on resources provided to accept their natural fluctuations and often random. These renewable energies include, photovoltaic, wind, biomass and geothermal, they are available in excess of the current energy needs of humankind.

Renewable energy resources do not increase the amount of greenhouse gas from the atmosphere during their operation. They also represent opportunity for isolated access to electricity regions. Standalone sources of renewable energy cannot meet the instant demand of energy, either due of lack level of energy source or its temporal variability.

Therefore, hybrid renewable energy can reduce the impact of uncertainties and variability of resources [2]. For ecological and economical development, the combination of

E-mail address: mohcene.ovi@gmail.com

ISSN: 1791-2377 @ 2017 Eastern Macedonia and Thrace Institute of Technology. All rights reserved. these renewable energy sources for a hybrid energy system called multi sources can be a good alternative to mono source systems. A hybrid system (solar - wind) can be very interesting when local conditions are favorable from the standpoint of: wind and sunshine [3].

The periods of the year with low sunshine correspond to those with the best wind potential. It is therefore clear that complementary wind and solar energy is desirable and that the coupling of these two energy sources with storage batteries is the safest and least expensive solution for autonomous systems [4].

The main difficulty associated with decentralized energy sources is that they generally do not participate in adjustment to these systems (voltage control, frequency, possibility of islanding function, etc.). This is especially true for renewable energy sources whose production is very unpredictable and fluctuating. The integration of distributed generation units in grid poses a number of problems:

Random and unpredictable producible (wind, solar); Load frequency control of Absence;

Voltage setting Absence;

Sensitivity to voltage dips;

In these years, several controller methods have been investigated by many researchers for the using of renewable energy sources connected to grid. The regulation of current or voltage is assured by special regulators such the different types as P, PI or PID presented in [5, 6-7]. However, regulators are designed using control techniques for perfectly linear models. These classic methods have some 
disadvantages such as difficulty in performance, and instability in operation. For overcoming these disadvantages, new methods such as the artificial, have been applied in research works [8, 9-10].

In 2008, Zhane Faminget al, [11] presented a nonlinear controller strategy called Passivity-Based Control "PBC" that has been applied for three-phase PV feed inverter. The $\mathrm{PBC}$ is simulated to evaluate performance. Simulation results are provided for $\mathrm{PBC}$ under fixed atmospheric condition that demonstrates can make the inverter provide currents to a utility with low harmonics.

In the other work [12], an active and reactive power control approach "PQ" has been presented for the inverter connected to grid using PV system; this method can provide a current with sinusoidal waveform and ensure a high-power factor. The model has been validated through several experiments performed on a $2.5 \mathrm{~kW}$ plant.

Moreover, Seul-Ki Kim et al [13] have studied the modeling and power control of a Wind/PV hybrid generation system connected to the electric distribution system. Furthermore, hybrid wind-solar connected to the grid using $\mathrm{AC} / \mathrm{DC}$ converters as distributed generation power sources has been presented by Saeed Jahdi and Loi Lei Lai [14].

This paper investigates the study of a hybrid system with two sources of PV / wind power and apply PSO Backstepping controller to address current and adjust the voltage and frequency with grid variables. The application of this controller method in this area should be so easy to use compared to other sand also presents a high effectiveness with the change of system parameters.

Backstepping controller depends on the system in matrix formulated form. Its design remains to select recursively some appropriate state variables as virtual inputs. In short, this method based for the chosen Lyapunov function that means less than zero "stabilize the system". It changed the fundamentals of reading the selection of these important constants in the system stability and three aspects are addressed:

The choice of the most suitable configuration;

Maximizing the use of both renewable resources;

Finally, determine the optimal size which depends mainly on the site climate data to determine the number of photovoltaic and wind generators and the battery capacity corresponding to a properly functioning hybrid system with minimal cost;

PSO proposed to adjusted Lyapunov function parameters; it is a technique that evolutionary uses a "population" of solutions candidate to develop an optimal solution of the problem. The degree of optimality is measured by a fitness function defined by the user. It is different from other methods of evolutionary computation in order that members of the public called " particles " are scattered in space of the problem [15].

The current paper presents the description of hybrid system setup before the mathematical modeling of Wind turbine and PV system, DC-DC Converter and Control Algorithm and completed by the Modeling of the Three Phase Grid Connected Hybrid System consist the PSO Backstepping Controller. The Simulation of the results has been also discussed.
The illustrated hybrid system includes two renewable generation sources, wind and solar. The wind turbine is used as primary energy sources, while the PV is used as a secondary power source. The system studied here is composed of a wind generator of $5.3 \mathrm{~kW}$, and a photovoltaic generator of $5.4 \mathrm{~kW}$. The general scheme of the hybrid system can be represented by Fig. 1 .

The system consists of two conversion chains:

A photovoltaic generator, a DC-DC power converter to adapt the generator to the load, a DC-AC converter for an AC voltage;

A wind generator, a Permanent Magnet Synchronous Generator "PMSG", a diode rectifier for the AC-DC conversion, DC-DC power converter to adapt the load to the wind generator and a DC / AC converter for an AC voltage then coupled to the grid;

Modeling of the conversion energy system

Modeling of the turbine

The studied system consists of a wind turbine comprising blades length $R(\mathrm{~m})$ driving a generator through a gain multiplier $K$ (torque constant) (Fig .1). Eq. 1 gives the torque created on the blades of the wind, the air density $\rho$ $(\mathrm{kg} / \mathrm{m} 3)$ with speed $V_{v}(\mathrm{~m} / \mathrm{s})[16,17]$.

$$
\left\{\begin{array}{l}
T_{\text {turb }}=\frac{1}{2} \cdot \rho \cdot \pi \cdot R^{3} \cdot C_{t}(\lambda) \cdot V_{v}^{2} \\
C_{p}(\lambda)=\lambda \cdot C_{t}(\lambda)
\end{array}\right.
$$

$C_{p}(\lambda)$ is the coefficient of power conversion, $\lambda$ and $C_{t}(\lambda)$ are respectively, the tip-speed ratio (specified speed), the coefficient of torque conversion.

Fig. 2 shows the influence of the wind speed and the rotational speed of the turbine on the power available from the generator shaft.

Power recover for a given wind speed depends on the rotational speed of the rotor. For each wind speed so there will be a speed at which the output power will be max illustrated in Fig. 3.

According to the Fig. 2 it is possible to observe that the maximum power is proportional to the cube of the wind speed. This is explained because the value of the maximum $C_{p}$ is constant for all wind speeds. Therefore, for a string of variable-speed conversion, and assuming that the setting allows to perfectly following the point of maximum $C_{p}$.The power in the shaft of the machine is given by the following equation (Eq. 2):

$$
\left\{\begin{aligned}
P_{\text {turbW }} & =\frac{1}{2} \cdot \rho \cdot \pi \cdot R^{3} \cdot C_{p}(\lambda) \cdot V_{v}^{3} \\
\Omega_{\text {mec }} & =\frac{\lambda_{\text {opt }} \cdot V_{v}}{R} \\
P_{\text {max }} & =K_{p, \max } \cdot V_{v}^{3} \\
K_{p, \text { max }} & =\frac{1}{2} \rho \cdot R^{3} \cdot C_{p, \text { max }}
\end{aligned}\right.
$$

\section{Where:}

$\lambda_{\text {opt }}$ : The optimal specific speed.

$\Omega_{m e c_{r e f}}$ : The reference rotating speed.

The PMSG dynamic model in a rotor reference frame is given by the following equation (Eq. 3) [18, 19]: 
Mohcene Bechouat, Moussa Sedraoui, Youcef Soufi, Laatra Yousfi, Abdelhalim Borni, Sami Kahla/ Journal of Engineering Science and Technology Review 10 (1) (2017) 91 - 99

$\left\{\begin{array}{l}V_{q}=-R_{S} \cdot i_{q}-L_{q} S \cdot i_{q}-\omega_{e} L_{q} \cdot i_{d}+\omega_{e} \cdot \emptyset_{m} \\ V_{d}=-R_{S} \cdot i_{d}-L_{d} S \cdot i_{q}-\omega_{e} L_{d} \cdot i_{q} \\ V_{q}=\frac{3 \cdot P}{2.2}\left(\emptyset_{m} \cdot i_{q}+\left(L_{d}-L_{q}\right) \cdot i_{q} \cdot i_{d}\right)\end{array}\right.$

With:

$\omega_{e}$ is the electric pulsation, $\emptyset_{m}$ is electric pulsation and $S$ is Laplace magnitude.

$L_{d}=L_{q}=L$ : stator inductances in the $d q$ axes.

Where:

$V_{b u s}$ is the voltage of the DC bus and $u c$ is a simple function of the DC/DC converter duty cycle, the equation system as follows (Eq. 4) [20, 21]:

$$
\left\{\begin{array}{l}
i_{q}=-\frac{R_{S}}{L} i_{q}-\omega_{e} \cdot i_{d}+\frac{\omega_{e} \cdot \emptyset_{m}}{L}-\frac{\pi \cdot V_{b u s} \cdot i_{q}}{3 \cdot \sqrt{3} \cdot L \cdot \sqrt{i_{d}^{2}+i_{q}^{2}}} \\
i_{d}=-\frac{R_{S}}{L} i_{d}-\omega_{e} \cdot i_{q}-\frac{\pi \cdot V_{b u s} \cdot i_{q}}{3 \cdot \sqrt{3} \cdot L \cdot \sqrt{i_{d}^{2}+i_{q}^{2}}}
\end{array}\right.
$$

Besides, assuming an ideal static conversion, the output current of the DC/DC converter can be readily determined equating its input and output power (Eq. 5):

$i_{d 1}=\frac{\pi}{2 \cdot \sqrt{3} \cdot L} \sqrt{i_{d}^{2}+i_{q}^{2}}$

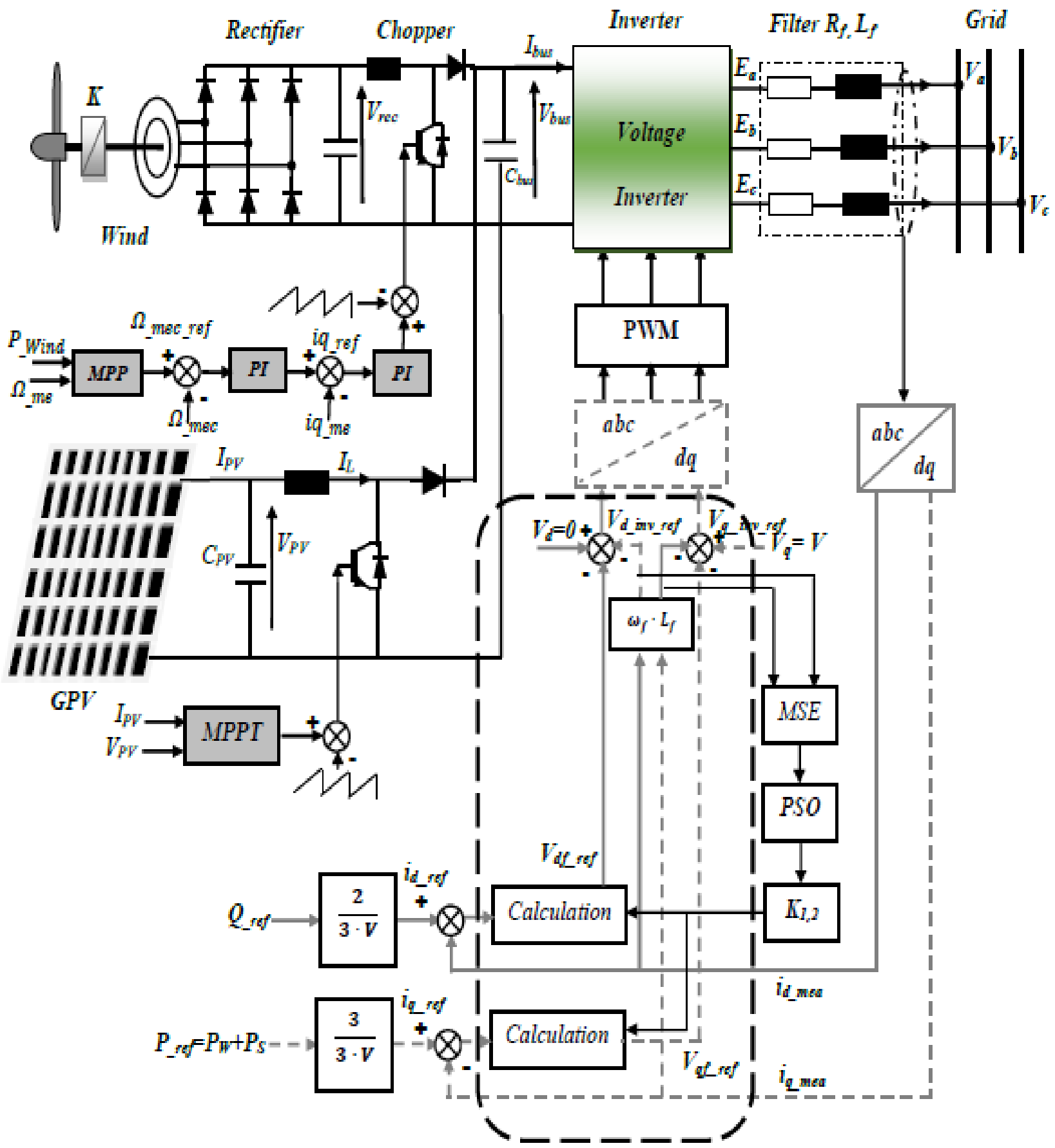

Fig.1 Configuration and control power of a PV/Wind hybrid system connected to grid 


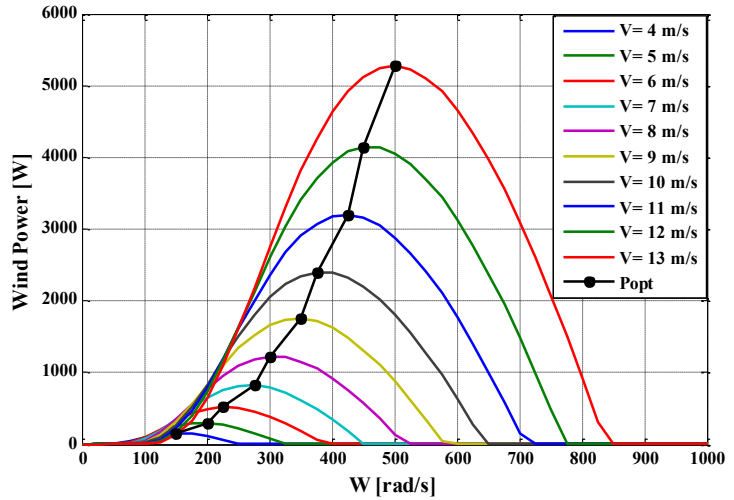

Fig. 2 Wind power curves for various winds

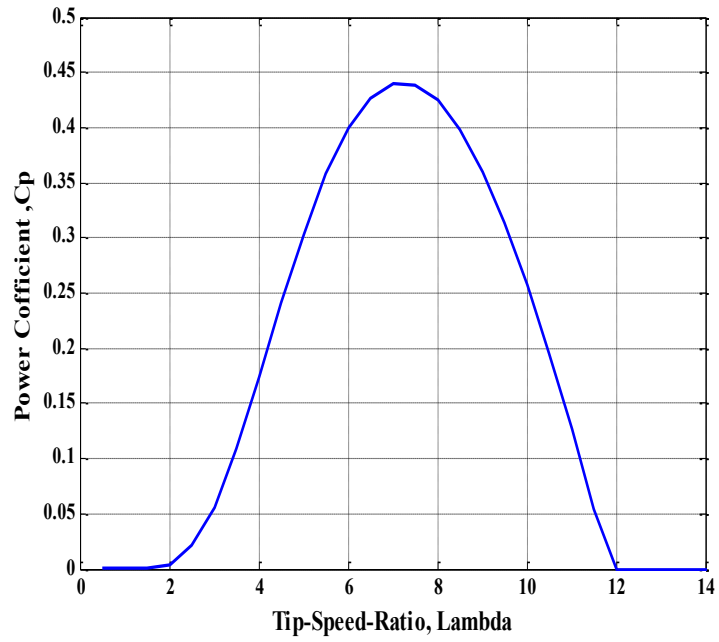

Fig. 3 Power coefficient as a function of the tip-speed-ratio

\subsection{Mathematical Modeling of PV}

Among the models exist in the literature, a developed model consider a characterized diode by its simplicity. The advantage of this model is that it allows directly using the data provided by the manufacturer in the data sheet of the panel.

A photovoltaic device can be modeled as an ideal source of current (constant) with a diode in different research works $[22,23]$ :

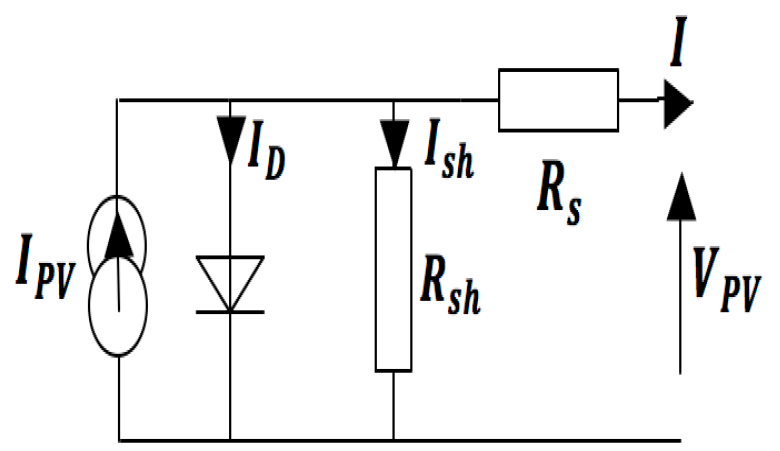

Fig. 4 Solar cell circuit

The equation describing the operating point of a solar cell can be expressed using the first Kirchhoff's law as follows (Eq. 6):

$$
I=I_{P V}-I_{0} \cdot\left[\exp \left(\frac{q \cdot\left(V_{P V}+I \cdot R_{S}\right)}{n \cdot K \cdot T}\right)-1\right]-\frac{V_{P V}+R_{S} \cdot I}{R_{S h}}
$$

\subsubsection{Analysis Parametric of PV system}

The external parameters that influence the behavior of a photovoltaic panel are the temperature of the cell and the received level of solar radiation.

\subsubsection{Irradiation influence}

Fig. 5 gives the P-V and I-V characteristics of a PV module according to the incident irradiation and at ambient temperature.
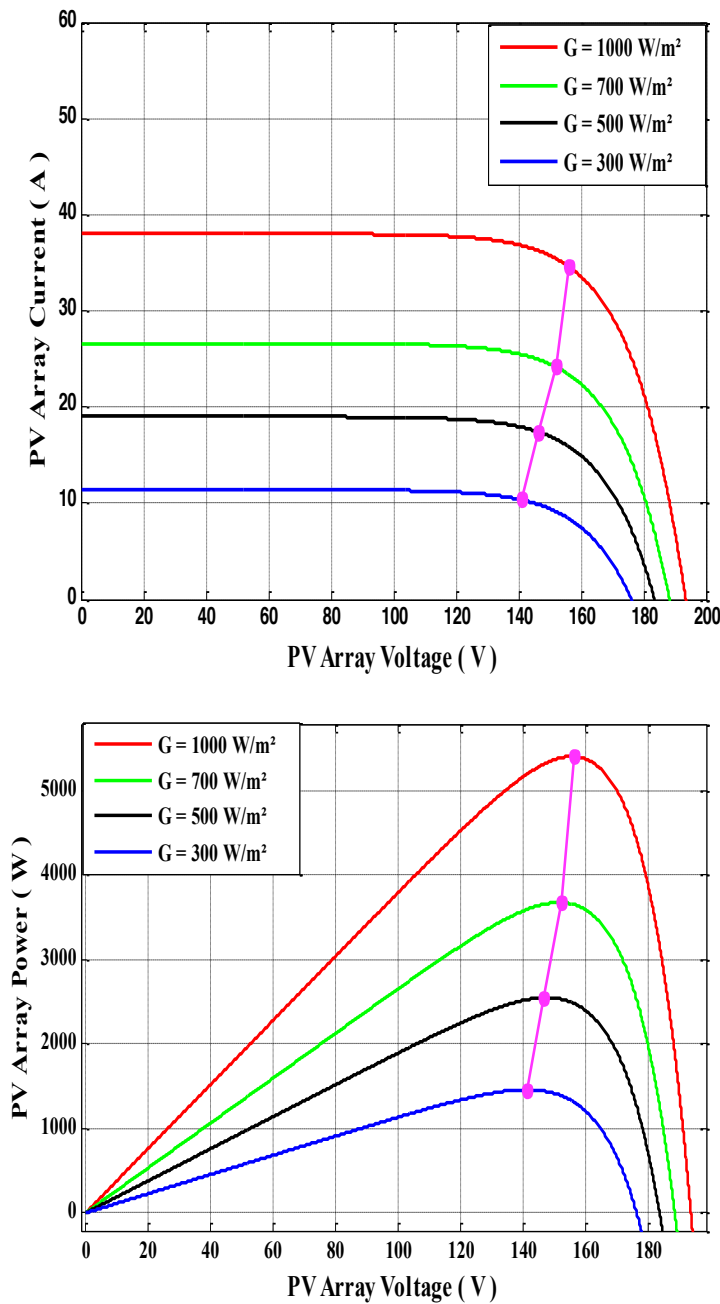

Fig.5 I-V, P-V curves as a function of irradiation

It can be noted that the changes in short-circuit current is proportional to the irradiation flux (Eq. 7). This influence results in an increase in the power available in the PV modules whenever the irradiation increases and each of irradiation values is a maximum electric power that could provide a PV module.

$I_{C C}=I_{C C}^{*} \cdot \frac{G}{G^{*}}+\alpha_{1} \cdot\left(T-T^{*}\right)$

\subsubsection{Temperature influence}

Fig. 6 shows the P-V and I-V characteristics for a constant irradiation and to the various temperature values. 

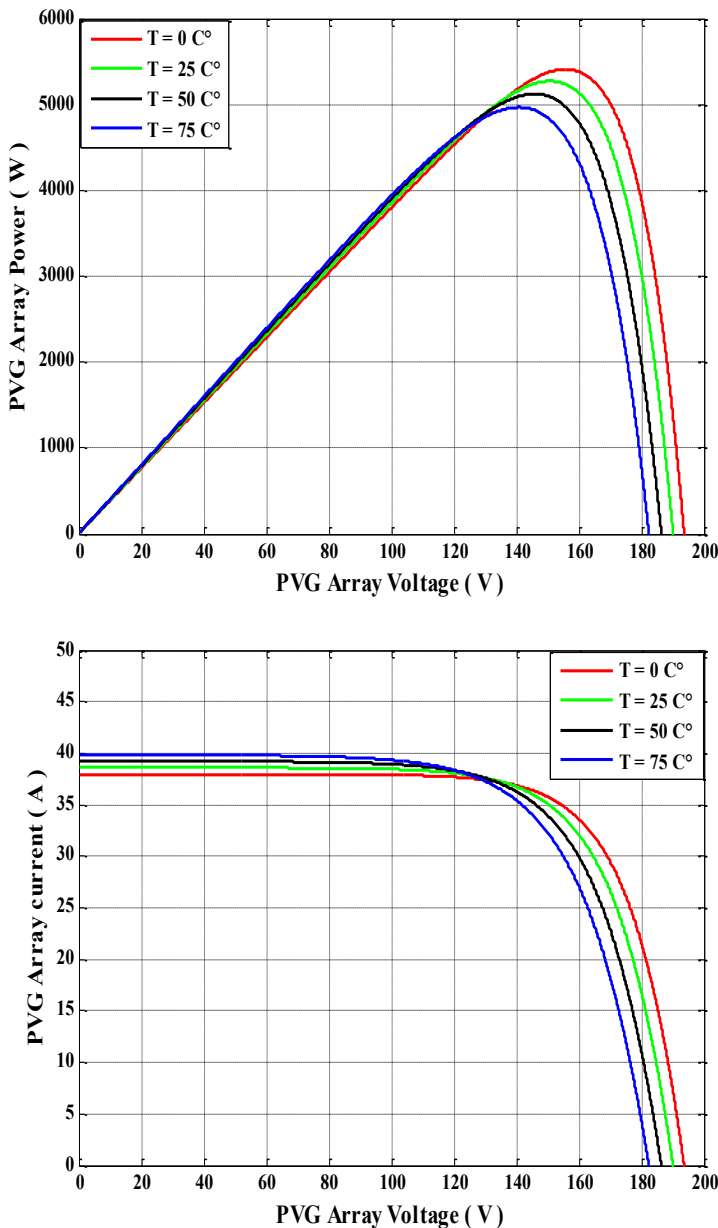

Fig.6 P-V, I-V curves as a function of temperature

Based on the above figures, it can be observed that the current $I_{c c}$ short tour varies little with temperature. By against the increase in temperature causes a reduction of the open circuit voltage and also results in a reduction of the maximum power available in the PV modules. Open-circuit voltage of a PV module based on the temperature and irradiation is given by the following relationship (Eq. 8):

$V_{C O}=V_{C O}^{*}+\alpha_{2} \cdot \Delta T-\alpha_{2} \cdot \Delta I_{C C} \cdot R_{S}$

With: $\Delta \mathrm{T}=\left(\mathrm{T}-\mathrm{T}^{*}\right)$ and $\Delta \mathrm{I}_{\mathrm{CC}}=\left(\mathrm{I}_{\mathrm{CC}}-\mathrm{I}_{\mathrm{CC}}^{*}\right)$

$V^{*}{ }_{C O}, I^{*}{ }_{C C}$ respectively represent the open circuit voltage and short circuit current at $T=25^{\circ} \mathrm{C}$ and $G=1 \mathrm{~kW} / \mathrm{m} 2$.

$\alpha_{1}, \alpha_{2}$ : Coefficient obtained empirically $\left(\mathrm{A} / \mathrm{C}^{\circ}\right),\left(\mathrm{V} /{ }^{\circ} \mathrm{C}\right)$.

$G^{*}$ : irradiation reference $1 \mathrm{~kW} / \mathrm{m} 2$

$T^{*}$ : Ambient temperature equal to $25^{\circ} \mathrm{C}$

\section{DC-DC Converter and Control Algorithm}

In order to make the most of that energy source (PV, wind) can provide, it should be necessary to function at the maximum power point. This is realized by incorporating a DC / DC converter to adjust the voltage across the panels and a second DC-DC converter connected to the rectifier output for the wind generator that corresponding to the point of optimal operation.
The purpose of this control is to control the voltage of the GPV and shaft speed PMG; therefore, the maximum power captured two sources.

The state equation that describes the DC-DC boost converter for the GPV is given by (Eq. 9) [24]:

$$
\left\{\begin{aligned}
C_{P V} \cdot \frac{d V_{P V}}{d t} & =i_{P V}-i_{L} \\
L \cdot \frac{d i_{l}}{d t} & =-\left(1-u_{c}\right) \cdot V_{b u s}-V_{j} \\
C_{b u s} \cdot \frac{d V}{d t} & =-\left(1-u_{c}\right) \cdot i_{L}-\frac{V_{b u s}}{R}
\end{aligned}\right.
$$

$V_{j}=V_{P V}, V_{j}$ is the GPV voltage or rectifier voltage.

Numerous methods of tracking the maximum power point tracking (MPPT) were developed in order to allow the system extracting the maximum power from the wind and photovoltaic generator. The chart of the $\mathrm{P} \& \mathrm{O}$ control is shown in Fig .7 [25].

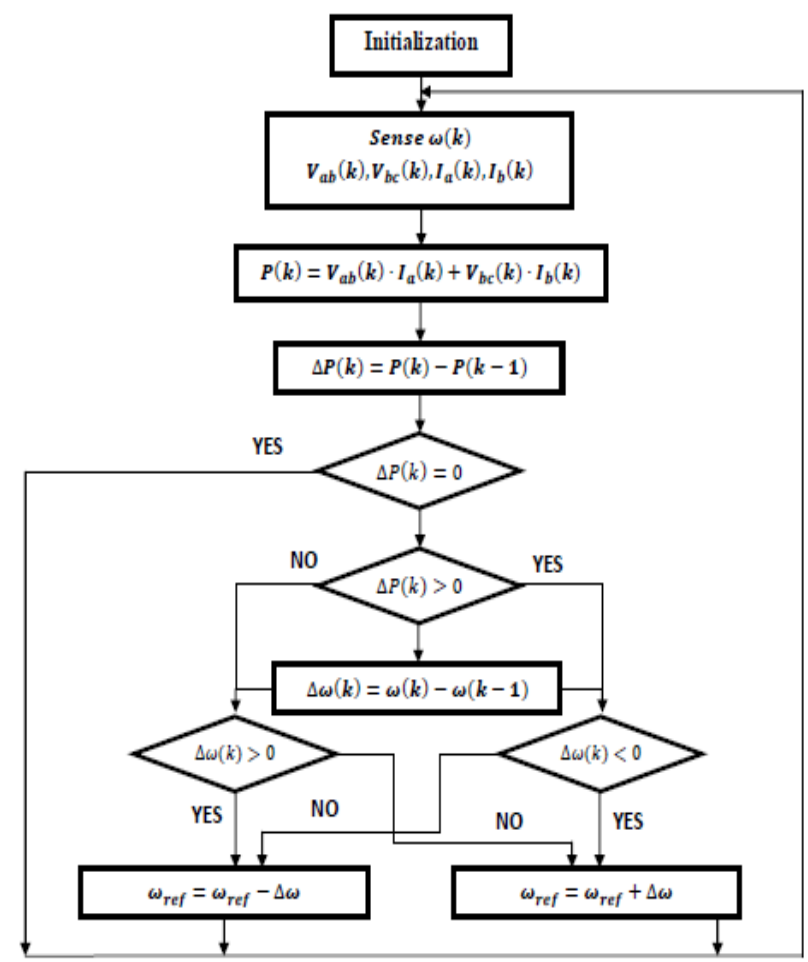

Fig.7 Flowchart of P\&O method for maximum power point tracking

The principle of this control algorithm is to generate disturbances by reducing or increasing the step speed and observe the effect on the power output of wind generator.

- $\quad d P / d \omega>0$, the speed is increased.

- $\quad d P / d \omega<0$, the speed in reduced.

For the GPV, we change the wind speed $(\omega)$, by the generator voltage $(\mathrm{V})$.

\section{Modeling of the Three Phase Grid Connected Hybrid System}

\subsection{Active and reactive power in the frame $d q$}

Fig. 8 shows the vector representation of the three-phase system and their equivalents vectors for turning marker $d q$. 


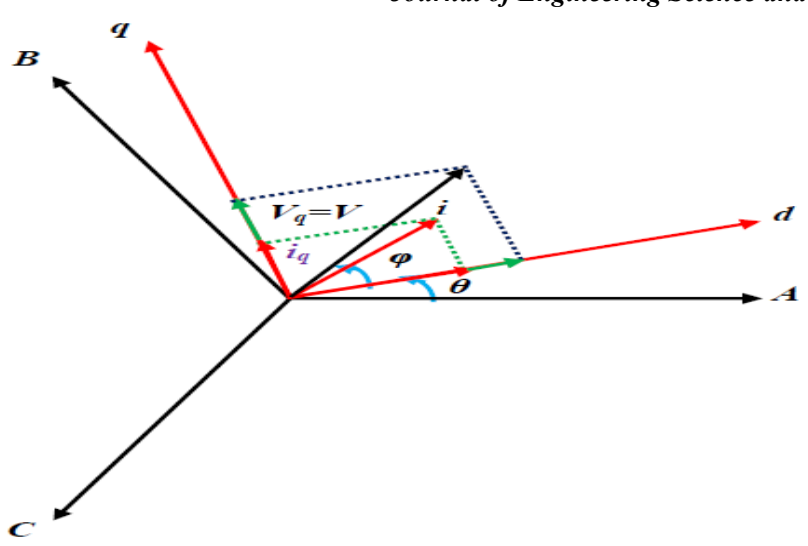

Fig.8 Definition of rotating reference frame

The state-space model of a three-phase grid connected hybrid system shown in Fig. 1 can be obtained by the equation described as follows (Eq. 10) [20]:

$\left\{\begin{array}{l}L_{f} \frac{d i_{a}}{d t}=-R_{f} \cdot i_{a}+V_{a_{-} i n v}-V_{a} \\ L_{f} \frac{d i_{b}}{d t}=-R_{f} \cdot i_{b}+V_{b_{-} i n v}-V_{b} \\ L_{f} \frac{d i_{c}}{d t}=-R_{f} \cdot i_{c}+V_{c \_i n v}-V_{c}\end{array}\right.$

Where the $V_{i-i n v}(i=a, b, c)$ are simple output voltage of the inverter given by (Eq. 11):

$\left[\begin{array}{l}V_{a_{\_} i n v} \\ V_{b_{\_} i n v} \\ V_{c_{\_} i n v}\end{array}\right]=\frac{1}{3} V_{\text {bus }}\left[\begin{array}{ccc}2 & -1 & -1 \\ -1 & 2 & -1 \\ -1 & -1 & 2\end{array}\right]\left[\begin{array}{l}f_{1} \\ f_{2} \\ f_{3}\end{array}\right]$

$f_{i}, i=1, \ldots 3$ : commutation function.

$V_{i}(i=a, b, c)$ is the Grid voltage.

As three-phase sinusoidal voltage is variable over time in the mathematical model of the three-phase $a b c$ coordinate system, we can use the matrix (Eq. 12)

$\mathrm{Q}_{\mathrm{abc} / \mathrm{dq} 0}=$
$\frac{2}{3}\left[\begin{array}{ccc}\cos \omega_{\mathrm{f}} \mathrm{t} & \cos \left(\omega_{\mathrm{f}} \mathrm{t}-120^{\circ}\right) & \cos \left(\omega_{\mathrm{f}} \mathrm{t}-240^{\circ}\right) \\ \sin \omega_{\mathrm{f}} \mathrm{t} & \sin \left(\omega_{\mathrm{f}} \mathrm{t}-120^{\circ}\right) & \sin \left(\omega_{\mathrm{f}} \mathrm{t}-240^{\circ}\right) \\ 0.5 & 0.5 & 0.5\end{array}\right]$

Transforming the equations system into the synchronous reference frame by using the park transformation matrices that is given by (Eq. 13):

$$
\left\{\begin{array}{l}
L_{f} \cdot \frac{d i_{d}}{d t}=-R_{f} i_{d}-\omega_{f} \cdot L_{f} \cdot i_{q}+V_{d_{\_} i n v}-V_{d} \\
L_{f} \cdot \frac{d i_{q}}{d t}=-R_{f} i_{q}-\omega_{f} \cdot L_{f} \cdot i_{d}+V_{q_{-} i n v}-V_{q}
\end{array}\right.
$$

The pulsation $\omega_{f}=2 \pi f, f:$ the frequency in hertz.

The instantaneous apparent power $S$ injected to the grid given by (Eq. 14):

$S=P+j \cdot Q$

Where $P$ (the active power) and $Q$ (the reactive power) are given by (Eq. 15):
$\left\{\begin{array}{l}P=\frac{3}{2}\left(V_{d} \cdot i_{d}+V_{q} \cdot i_{q}\right) \\ Q=\frac{3}{2}\left(V_{q} \cdot i_{d}+V_{d} \cdot i_{q}\right)\end{array}\right.$

The rotating frame of orientation serves to obtain a separate control (decoupled) of active and reactive power. As seen in Fig. 9, $V_{q}=V$ and $V_{d}=0$, so that the equation of the active and reactive power can be simplified in the rotating frame as (Eq. 16):

$\left\{\begin{array}{l}P=\frac{3}{2} V \cdot i_{q} \\ Q=\frac{3}{2} V \cdot i_{d}\end{array}\right.$

The active power can be controlled by $i_{q}$ and the reactive power can be controlled by $i_{d}$. S

\section{The grid control PSO Backstepping}

\subsection{Backstepping Controller}

The base idea of Backstepping approach is stabilized the system from the first sub system by stabilizing function known via a Lyapunov function selected, and then add to its input integrator. The same procedure for the next under increased system and so on for the successive subsystems to finally reach a global Lyapunov function giving overall control law that stabilizes the system.

The Backstepping technique is relatively a new control method of nonlinear systems. It allows sequentially and systematically, by choosing a Lyapunov function to determine the system control law [26, 27].

The purpose of the order is to achieve convergence towards zero errors thus achieving the stability and balance of the system which allows the output to follow a reference. Consider the following coupling voltages (Eq. 17):

$$
\left\{\begin{aligned}
e_{d} & =L_{f} \cdot \omega_{f} \cdot i_{d} \\
e_{q} & =-L_{f} \cdot \omega_{f} \cdot i_{q} \\
V_{d f} & =V_{d}-V_{d_{-} i n v}-e_{q} \\
V_{q_{f}} & =V_{q}-V_{q_{-} i n v}-e_{d}
\end{aligned}\right.
$$

The differential equations (Eq. (13)) can be simplified to (Eq. 18):

$\left\{\begin{array}{l}L_{f} \cdot \frac{d i_{d}}{d t}=-R_{f} \cdot i_{d}+V_{d f} \\ L_{f} \cdot \frac{d i_{q}}{d t}=-R_{f} \cdot i_{q}+V_{q f}\end{array}\right.$

We define the errors $e_{1}$ and $e_{2}$ representing errors between the actual currents and references currents (Eq. 19):

$\left\{\begin{array}{l}e_{1}=i_{d \_r e f}-i_{d} \\ e_{2}=i_{q_{-} r e f}-i_{q}\end{array}\right.$

And their dynamics are given by (Eq. 20):

$\left\{\begin{array}{l}\dot{e_{1}}=\dot{i}_{d_{-} r e f}-l_{d}=l_{d_{-} r e f}+\frac{1}{L_{f}}\left(R_{f} \cdot i_{d}-V_{d f}\right) \\ \dot{e_{2}}=\dot{\imath}_{q_{-} r e f}-l_{q} \cdot l_{q_{-} r e f}+\frac{1}{L_{f}}\left(R_{f} \cdot i_{q}-V_{q f}\right)\end{array}\right.$

The Lyapunov function is chosen such that (Eq. 21): 
$v=\frac{1}{2}\left(e_{1}^{2}+e_{2}^{2}\right)$

Its derivative is (Eq. 22):

$$
\left\{\begin{aligned}
\dot{v}=\dot{e}_{1} e_{1}+\dot{e}_{2} e_{2} & \\
\dot{v} & =e_{1}\left(l_{d_{\text {ref }}}+\frac{1}{L_{f}}\left(R_{f} i_{d}-V_{d f}\right)\right)+ \\
& e_{2}\left(l_{q_{-}} \dot{r e f}+\frac{1}{L_{f}}\left(R_{f} i_{q}-V_{q f}\right)\right)
\end{aligned}\right.
$$

Pursuing the objectives is achieved $(\dot{\mathrm{v}}<0)$ by selecting the references of the components of the voltages that represent the stabilizing function as follows (Eq. 23):

$$
\left\{\begin{array}{l}
V_{d f_{-} r e f}=L_{f}\left(K_{1} e_{1}+\iota_{d_{-} \text {ref }}\right)+R_{f} i_{d} \\
V_{q f_{-} r e f}=L_{f}\left(K_{2} e_{2}+\iota_{q_{-} \text {ref }}\right)+R_{f} i_{q}
\end{array}\right.
$$

From (Eq. (17)) can make (Eq. 24):

$$
\left\{\begin{array}{l}
V_{d_{-} i n v_{-} r e f}=V_{d}-V_{d f_{-} r e f}-e_{q} \\
V_{q_{-} i n v_{-} r e f}=V_{q}-V_{q f_{-} r e f}-e_{d}
\end{array}\right.
$$

Where $K_{1,2}$ are positives constants. Stability control is obtained if and only if the matrix is hurwitzienne (Roots with negative real parts) which is verified by a good selection of gains $\left(K_{1,2}>>0\right)$ [28]. This choice is heuristic, for these we propose the PSO algorithm to calculate $K_{1,2}$ in the next Section.

\subsection{PSO and learning algorithm}

PSO is first introduced by Kennedy and Eberhart in 1995 [29]. PSO is characterized as a simple structure, easy to implement, computationally efficient and quick convergence than other stochastic methods such as genetic algorithms "GAs".

PSO uses particles which represent potential solutions of the problem. Each particles fly in search space at a certain velocity which can be adjusted in light of proceeding flight experiences. The projected position of $i^{\text {th }}$ particle of the swarm $x_{i}$, and the velocity of this particle $v_{i}$ at $(i+1)^{\text {th }}$ iteration are defined as the following two equations(Eq. 25) in this study [30]:

$$
\left\{\begin{array}{l}
v_{i D}^{t+1}=w \cdot v_{i D}^{t}+c_{1} \cdot r_{1}\left(p_{i D}^{t}-x_{i D}^{t}\right)+c_{2} \cdot r_{2}\left(g_{i}^{t}-x_{i D}^{t}\right) \\
x_{i D}^{t+1}=v_{i D}^{t+1}+x_{i D}^{t}
\end{array}\right.
$$

where, $i=1, \ldots, n$ and $n$ is the size of the swarm, $D$ is dimension of the problem space, $w$ is the momentum or inertia, $c_{1}$ and $c_{2}$ are positive constants, $r_{1}$ and $r_{2}$ are random numbers which are uniformly distributed in $[0,1], t$ determines the iteration number, $p_{i}$ represents the best previous position (the position giving the best fitness value) of the $i^{\text {th }}$ particle, $g$ represents the best particle among all the particles in the swarm. PSO can be depicted as follows [29, 30]:

- Initialize a population of particles with random positions and velocities on $D$-dimensions in the problem space,

- Evaluate desired optimization fitness function in $D$ variables for each particle,

- Compare particle's fitness evaluation with its best previous position. If current value is better, then set best previous position equal to the current value, and $\mathrm{p}_{\mathrm{i}}$ equals to the current location $x_{i}$ in $D$-dimensional space,

- Identify the particle in the neighborhood with the best fitness so far, and assign its index to the variableg,

- Change velocity and position of the particle according to (Eq. (25)),

- Loop to step 2 until a criterion is met or end of iterations.

- At the end of the iterations, the best position of the swarm will be the solution of the problem. It is not possible to get an optimum result of the problem always, but the obtained solution will be certainly an optimal one.

To accelerate the convergence of PSO, it was proposed to find a better solution in a minimum computation time and accuracy. We calculate the best solution, on minimizing a certain criterion (objective function) such as the mean square error $(\boldsymbol{M S E})$ that can be calculated by the following equation (Eq. 26):

$\boldsymbol{M S E}=\frac{1}{N T} \sum_{i=1}^{N}\left(e_{1}^{2}+e_{2}^{2}\right)$

Where:

$N$ : is the total number of samples,

$T$ : the sampling time.

The block diagram shows the strategy calculated $K_{1,2}$ presented in Fig.9:

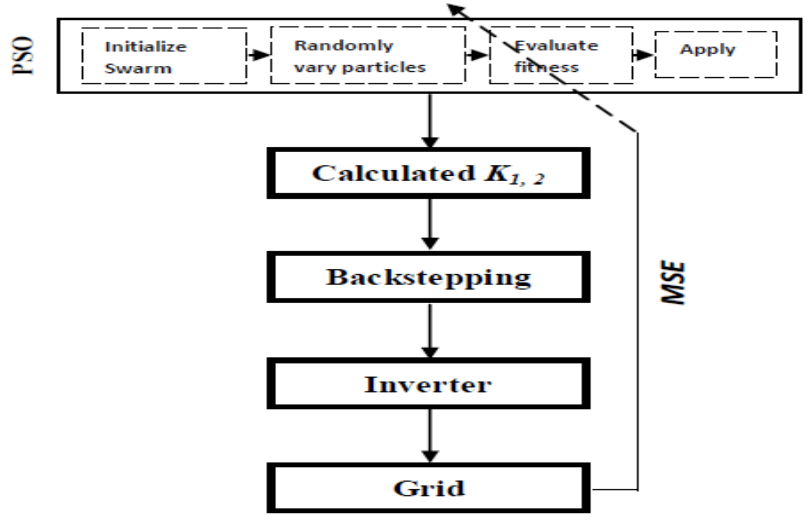

Fig.9 Distributed PSO Backstepping concept

\section{Results and discussion}

In order to investigate the proposed current controller performance, block diagram shown in Fig. 1 is simulated by using power system block set in Matlab/Simulink. The simulation results are considered by a variation in the irradiation and the wind speed as presented in Fig. 10, Fig. 11 respectively. Also it assume the resistance of the output reactor and internal resistance of the system $R_{f}=0.9 \Omega$, output reactor $L_{f}=0.9 \mathrm{mH}$, frequency $f=50 \mathrm{Hertz}$.The phase voltage amplitude of three phase balanced voltage source is $800 \mathrm{~V}$, the injecting damping is $5 \Omega$, the capacitor is $22000 \mu \mathrm{F}$. The best $K_{1}=10^{3}$ and $K_{2}=10^{5}$ are calculated by PSO for balanced voltage $800 \mathrm{~V}$. Where the following tuning parameters were used in PSO algorithm:

- Swarm size:100

- Maximum iteration number: $t_{\max }=200$ 
- Inertia factor: $w=0.90$

- Cognitive learning rate: $c_{1}=0.25$

- $\quad$ Social learning rate: $c_{2}=1.25$

We set desired reactive power for zero; the current waveforms of inverter output are shown in Fig. 12.The waveforms for comparing active power and reactive power of inverter output with expected value, which under condition of Fig. 12, are shown in Fig. 13, from it we can see that the system transition time is very short and the tracking results are more accurate, also Fig. 14 shows the injected currents to grid where there is low harmonic distortion as required by the standards of a system grid connection.

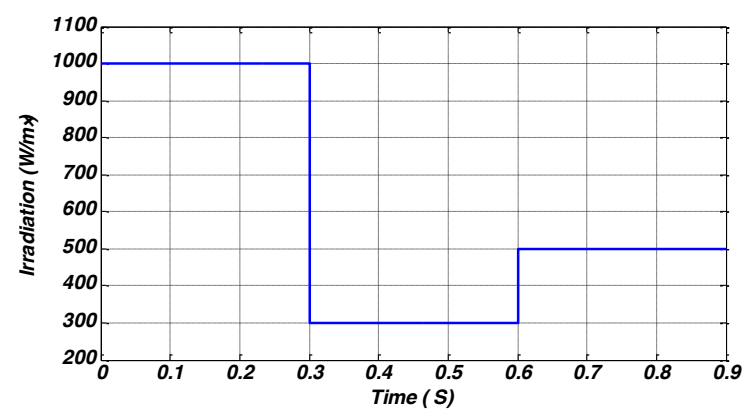

Fig.10 Irradiation variation

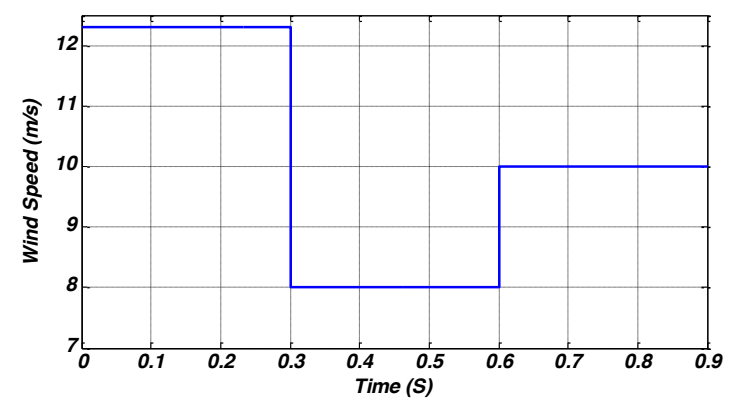

Fig.11 Wind Speed variation

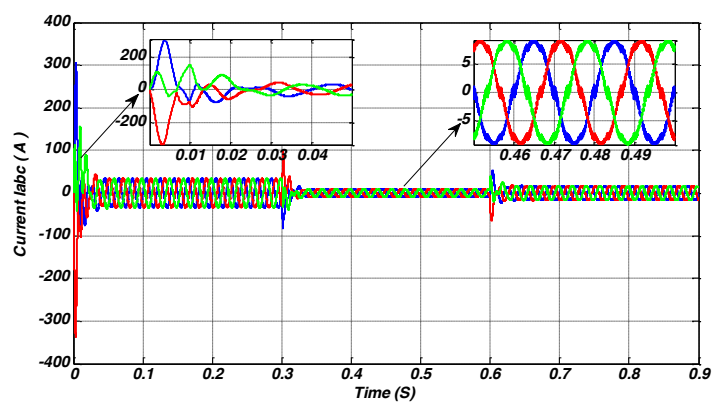

Fig.12 The output phase currents of inverter

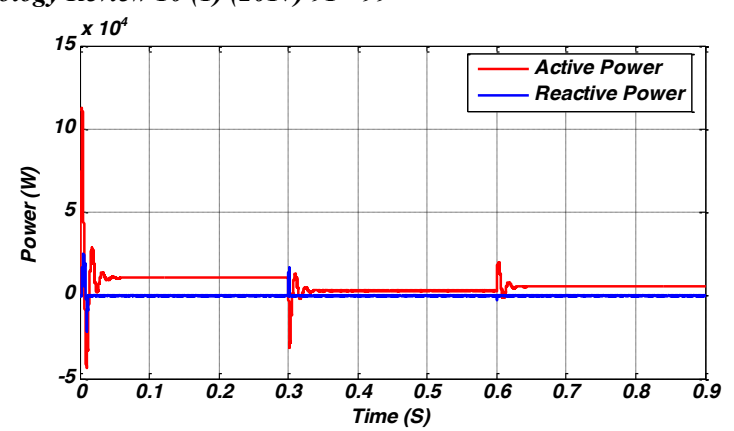

Fig.13 Comparison active and reactive power

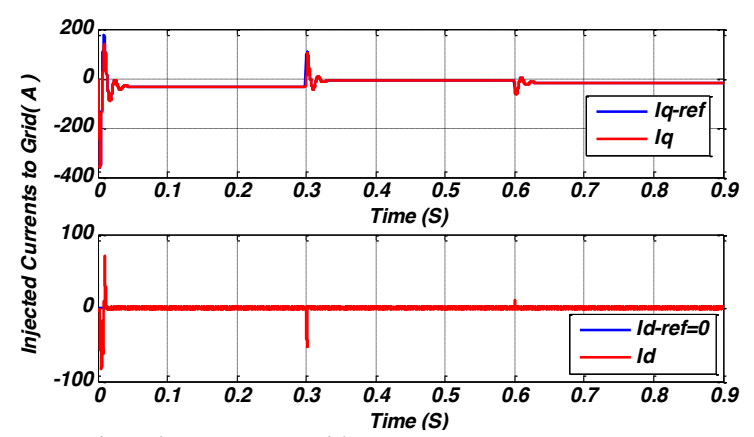

Fig.14 Injected currents to Grid

\section{Conclusion}

It has been found in the current study that:

The PSO Backstepping controller was quite simple;

The PSO relatively has adjustable Backstepping parameters for Lyapunov function gains, and the control effect was better;

The PSO Backstepping can make the system process better static and dynamic characteristic, while the reactive power can achieve the desired one;

The PSO Backstepping applied to PV/Wind hybrid connected to grid system can be implemented easily when its design is simple.

This is an Open Access article distributed under the terms of the Creative Commons Attribution Licence

\section{References}

1. World Wind Energy Association (WWEA), World wind energy report 2008, Report, Germany, February 2009.

2. M. Sharafi, T. Y. ELMekkawy, Multi-objective optimal design of hybrid renewable energy systemsusing PSO-simulation based approach, Renewable Energy, Vol.68, pp.67-79, 2014.

3. K. Karabacak, N. Cetin, Artificial neural networks for controlling wind-PV power systems: A review, Renewable and Sustainable Energy Reviews, Vol.29, pp.804-827, 2014.

4. B. Robyns, A. Davigny, C. Saudemont, Methodologies for supervision of Hybrid Energy Sources based on Storage Systems A survey, Mathematics and Computers in Simulation, Vol.91, pp.52-71, 2013.
5. N. A.Rahim, K. Chaniago, and J. Selvaraj, Single-Phase SevenLevel Grid-Connected Inverter for Photovoltaic System, IEEE Trans. Ind. Electron, Vol.58, No.06, pp.0278-0046, June. 2011.

6. J. Dannehl, C. Wessels, and F. Wilhelm Fuchs, Limitations of Voltage-Oriented PI Current Control of Grid Connected PWM Rectifiers With LCL Filters, IEEE Trans. Ind. Electron, Vol. 56, No.02, pp.0278-0046, Feb. 2009.

7. A.H.M.A. Rahim, E.P. Nowicki, Performance of a grid-connected wind generation system with a robust susceptance controller, Electric Power Systems Research, Vol.81, pp.149-157, 2011.

8. N. Ammasai Gounden, S. Ann Peter, H. Nallandula, S. Krithiga, Fuzzy logic controller with MPPT using line-commutated inverter 
Mohcene Bechouat, Moussa Sedraoui, Youcef Soufi, Laatra Yousfi, Abdelhalim Borni, Sami Kahla/

Journal of Engineering Science and Technology Review 10 (1) (2017) 91 - 99

for three-phase grid-connected photovoltaic systems, Renewable Energy, Vol. 34, pp.909-915, 2009.

9. W. Al-Saedi, S. W.Lachowicz, D. Habibi, O. Bass, Power flow control in grid-connected microgrid operation using Particle Swarm Optimization under variable load conditions, Electrical Power and Energy Systems, Vol.49, pp.76-85, 2013.

10. H. Boumaaraf, A. Talha, O. Bouhali, A three-phase NPC gridconnected inverter for photovoltaic applications using neural network MPPT, Renewable and Sustainable Energy Reviews, Vol.49, pp.1171-1179, 2015.

11. Z. Faming, W. Jun, W. Gang, Z. Baoli, Q. Linin, Stady on nonlinear control of PV parallel feed inverter, May, Vol.15, No.03, pp.296-298, 2008.

12. N. Hamrouni, M. Jraidi, A. Chérif, New control strategy for 2-stage grid-connected photovoltaic power system, Renewable Energy, Vol.33, pp.2212-2221, 2008

13. S. Ki Kim, E.S. Kim and J.B. Ahn, Modeling and Control of a grid connected wind/PV hybrid generation system, In: Proc. of Transmissionand Distribution conference and Exhibition 2005/2006 IEEE PES, Dallas, TX, pp.1202 - 1207 , 21-24 May 2006.

14. S. Jahdi, L. L. Lai, and D. Nankoo, Grid integration of wind-solar hybrid renewables using AC/DC converters as DG power sources, In: Proc. of IEEE World Congress on Sustainable Technologies (WCST 11), IEEE Press, pp. 171-177, 2011.

15. J.H. Chen, H.T. Yau, T.H. Hung, Design and implementation of FPGA-based Taguchi-chaos-PSO suntracking systems, Mechatronics, Vol.25, pp.55-64, 2015.

16. B. Robyns, A. Davigny, C. Saudemont, Methodologies for supervision of Hybrid Energy Sources based on Storage Systems A survey, Mathematics and Computers in Simulation, vol.91, pp.52-71, 2013.

17. D. Rekioua, Hybrid Wind Systems, Wind Power Electric Systems, Modeling, Simulation and Control, pp.163-183, Springer Verlag, London, 2014.

18. A. Dahbi, M. Hachemi, N. Nait-Said, M.S. Nait-Said, Realization and control of a wind turbine connected to the grid by using PMSG, Energy Conversion and Management, Vol.84, pp.346353, 2014.

19. F. Jaramillo-Lopez, G. Kenne, F. Lamnabhi-Lagarrigue, A novel online training neural network-based algorithm for wind speed estimation and adaptive control of PMSG wind turbine system for maximum power extraction, Renewable Energy, Vol.86, pp. 3848, 2016.

20. Y. Errami, M. Ouassaid, M. Cherkaoui and M. Maaroufi, Sliding Mode Control Scheme of Variable Speed Wind Energy
Conversion System Based on the PMSG for Utility Network Connection, Advances and Applications in Sliding Mode Control systems, Vol.576, pp. 167-200, Springer International Publishing, November 2014.

21. H.S. Ko, Modeling and Control of PMSG-BasedVariable-Speed Wind Turbine, pp.3-21, Springer International Publishing Switzerland, August 2014

22. S. Daraban, D. Petreus , C. Morel, A novel MPPT (maximum power point tracking) algorithm based on a modified genetic algorithm specialized on tracking the global maximum power point in photovoltaic systems affected by partial shading, Energy, Vol.74, pp.374-388, 2014

23. S. Li, A MPPT control strategy with variable weather parameter and no DC/DC converter for photovoltaic systems, Solar Energy, Vol.108, pp.117-125, 2014.

24. B. Bendib, F. Krim, H. Belmili, M. F. Almi, S. Boulouma, Advanced Fuzzy MPPT Controller for a stand-alone PV system, Energy Procedia, Vol.50, pp.383 - 392, 2014.

25. P. Mohanty, G.Bhuvaneswari, R. Balasubramanian, N.K. Dhaliwa, MATLAB based modeling to study the performance of different MPPT techniques used for solar PV system under various operating conditions, Renewable and Sustainable Energy Reviews, Vol.38, pp.581-593, 2014.

26. N. Sghaier, R. Trabelsi, S. Gdaim, B. Bossoufi, M. F. Mimouni, Backstepping Control of Induction Motor Using Xilinx System Generator: FPGA Based Implementation, International Journal of Emerging Sciences, Vol.3, No.03, pp.289-302, September 2013.

27. S. Chaouch, M.S. Nait-Said, A. Makouf and L. Cherifi, Backstepping Control based on Lyapunov Theory for Sensorless Induction Motor with Sliding Mode Observer, ARISER, Vol. 4 , pp. 19-27, No.01, 2008.

28. R. Trabelsi, A. Khdedhder, M. Faouzi Mimouni and F. M'salhi, An adptative Backstepping observer for on-line rotor resistance adaptation, International Journal of Sciences and techniques of Automatic Control \& Computer engineering.IJ-STA, Vol.4, No.01, pp. 1246-1267, July 2010.

29. J. Kennedy, R. Eberhart, Particle swarm optimization, In: Proc.IEEE Int. Conf. Neural Networks (ICNN'95), Vol. IV, Perth, Australia, p p. 1942-1948, 1995.

30. T. Zhou and W. Sun, MPPT Control Method of PV System with PSO Algorithm Based on Minimal Particle Angles, In: Proc. of the International Conference on Information Technology and Software Engineering, Springer-Verlag Berlin Heidelberg, pp.755-763, 2013. 